Article

\title{
Temporal and Spatial Differentiation of Cultivated Land and Its Response to Climatic Factors in Complex Geomorphic Areas-A Case Study of Sichuan Province of China
}

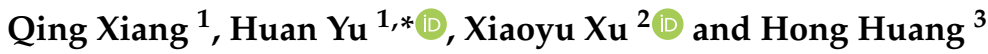 \\ 1 College of Earth Science, Chengdu University of Technology, Chengdu 610059, China; \\ xiangqing950211@163.com \\ 2 Department of Geography and Environmental Resources \& Environmental Resources and Policy, \\ Southern Illinois University Carbondale, Carbondale, IL 62901, USA; xiaoyu.xu@siu.edu \\ 3 College of Tourism and Urban-Rural Planning, Chengdu University of Technology, Chengdu 610059, China; \\ huanghong940325@163.com \\ * Correspondence: yuhuan10@cdut.edu.cn
}

Citation: Xiang, Q.; Yu, H.; Xu, X.; Huang, H. Temporal and Spatial Differentiation of Cultivated Land and Its Response to Climatic Factors in Complex Geomorphic Areas-A Case Study of Sichuan Province of China. Land 2022, 11, 271. https:// doi.org/10.3390/land11020271

Academic Editor: Nir Krakauer

Received: 9 January 2022

Accepted: 9 February 2022

Published: 10 February 2022

Publisher's Note: MDPI stays neutral with regard to jurisdictional claims in published maps and institutional affiliations.

Copyright: (C) 2022 by the authors. Licensee MDPI, Basel, Switzerland. This article is an open access article distributed under the terms and conditions of the Creative Commons Attribution (CC BY) license (https:// creativecommons.org/licenses/by/ $4.0 /)$.

\begin{abstract}
Analyzing the distribution characteristics and influencing factors of cultivated land in complex geomorphic areas is significant in evaluating the agricultural farming environment and formulating cultivated land protection measures. This study extracted cultivated land information based on multi-source remote sensing data, and analyzed the geomorphic differentiation of cultivated land distribution and climate response from 2000 to 2020 using the Gini coefficient, spatial autocorrelation analysis and geographic detector. The results show that cultivated land is mainly distributed in low-altitude hills and low-altitude small undulating mountains, and secondarily in low-altitude alluvial and proluvial plains and platforms. Moreover, from 2000 to 2020, the cultivated land in the high-altitude and high-altitude undulating mountains and medium and high-altitude undulating mountains in the Northwest Plateau of Sichuan showed an upward trend, while the cultivated land in the Sichuan Basin mainly increased from the north and south to the middle of the basin. In addition, the highest temperature has the strongest ability to explain the spatial heterogeneity of cultivated land. From the calculation results of the influence coefficient of a single climatic factor and the combined effect of multiple climatic factors, the main factors that affect the distribution of cultivated land are different in different geomorphological regions. Finally, it is proposed to formulate a long-term strategy for agricultural production to adapt to climate change in complex geomorphic areas in order to reduce the negative impact of environmental change on agricultural production.
\end{abstract}

Keywords: cultivated land differentiation; spatiotemporal evolution; climatic factors; geographic detector

\section{Introduction}

Cultivated land is one of the most important types of land use and is key to ensuring food security, ecological security, and regional development. The formation and existence of cultivated land are affected by climate, terrain, soil and other conditions. Geomorphic characteristics largely determine the conditions of temperature, rainfall and moisture in the local environment, affecting the development, quality and distribution of cultivated land. Therefore, it is of great theoretical and practical significance to explore the law of cultivated land differentiation at the scale of a geomorphological area, and to further excavate the response of cultivated land geomorphological differentiation to climate factors such as temperature, rainfall, humidity, and wind speed.

At present, researchers have conducted many studies on regional and global cultivated land changes at different spatial and temporal resolutions [1,2]. At the regional and national level, the spatial resolution of the land use map has been improved to analyze cultivated land change. For example, a land use map with $1 \mathrm{~km}$ spatial resolution was used to evaluate 
the spatial pattern of agricultural land in Brazil [3], China [4], and Europe [5]. A 30-m resolution land use map was developed to analyze the Usangu basin [6], central and eastern Iowa [7], northern Ghana [8], the Kabul River Basin [9] and Nigeria [10]. The existing studies are all large-scale regional studies, ignoring the impact of local topographic characteristics. As an important factor affecting the distribution and change of cultivated land, topographic characteristics have attracted extensive attention because of their important impact on the quantity, quality and ecosystem health of cultivated land. For agricultural cultivated land resources, comparing their topographic differentiation characteristics and dynamic evolution laws is a prerequisite for assessing the impact of regional development on the agricultural farming environment and formulating cultivated land protection measures.

Although various data sets for cultivated land distribution have been established worldwide, the comparative analysis of the most commonly used data sets has revealed large inconsistencies and uncertainties [11]. This is because the uncertainty of agricultural land cover classification is often greater than that of other categories. Complex landform areas are relatively unstable areas in agricultural production, so it is necessary to select products suitable for monitoring farmland. In this study, more accurate and appropriate cultivated land distribution data were obtained by integrating TM5, ETM+, and oli multispectral images from the United States Land Resources Satellite (Landsat), the multispectral images from the China environmental disaster reduction satellite (HJ-1), and 16-m resolution GaoFen-1 (GF-1) multispectral images.

In addition, existing studies confirmed that cultivated land patterns are sensitive to climatic changes and other natural factors [12-14]. Determining the driving force behind cultivated land change has become a hot spot in the field of land use and land cover change, agriculture and food security. Quantitative assessment of the contribution of climatic changes and human activities to temporal and spatial changes in farmlands is an important scientific topic in the field of climatic change and Land Surface System Science $[15,16]$. However, the geomorphic differentiation law of the impact of climatic factors on cultivated land is rarely revealed. Most of the existing studies focus on large-scale changes in cultivated land, and few studies compare the temporal and spatial transfer process of cultivated land and its climate response characteristics.

Correctly analyzing the distribution characteristics of cultivated land in different geomorphological regions and discussing the impact of climate factors on cultivated land for different geomorphic regions are two important difficulties that must be solved when choosing a research method.The methods to identify the spatial differentiation of cultivated land include nearest neighbor distance index, kernel density estimation, spatial interpolation and Getis-Ord $G^{*}$ statistical index, used to determine the concentration intensity of cultivated land elements, identify high-value agglomeration areas and visualize agglomeration differentiation [17]. However, the difference is that the first three methods are based on specific statistical rules and select part or all of the high-value agglomeration areas as "hot spots", which is limited by the inability to accurately identify the hot spots of cultivated land change from the level of statistical significance. The Getis-Ord $G^{*}$ statistical index can intuitively identify the hot spots of cultivated land change according to hot spot statistical significance parameters, with strong accuracy. In addition, although the existing research work focuses on the impact of climate and environmental factors on the distribution of cultivated land, there is still a lack of comprehensive comparison between factors and variable combinations, most adopt correlation or regression statistical methods, and the quantitative attribution of the impact and interaction of multiple climatic factors is relatively weak. The Geographic detectors method can reveal the driving force behind geographical phenomena by detecting their spatial stratification heterogeneity. The core assumption is that, if an independent variable has an important impact on a dependent variable, the spatial distribution of the independent variable and the dependent variable have strong consistency [18]. This method has been extensively used in the social $[19,20]$ and environmental [21-23] sciences. In this study, taking the spatial distribution of geomorphic types as the macro background, the multi factor quantitative attribution affecting 
the distribution of cultivated land is carried out with the help of the geographic detector method, in order to identify the dominant climatic factors and interactions in different geomorphic types of area, and put forward climate and environmental adaptation policies for crop production in different geomorphic areas.

Therefore, the specific objectives of this study are to: (1) analyze the distribution law of cultivated land in complex geomorphic areas; (2) compare the geomorphic differentiation characteristics of temporal and spatial transfer of cultivated land in 2000-2010 and 2010-2020; (3) reveal the response law of climatic factors for cultivated land distribution in different geomorphic areas.

\section{Data and Methods}

\subsection{The Study Area}

Sichuan is located in the transition zone between the first and the second ladder in China (Figure 1). The terrain is complex and diverse, dominated by mountains and plateau, followed by hills and limited plains. The Western Sichuan area is dominated by primitive mountainous landforms and high mountain canyon, while the southwestern area is $\mathrm{s}$ sub-high mountain and middle mountain canyon area. The eastern basin is dominated by plain and hilly landform, and the mountainous area at the edge of the basin is dominated by medium and low mountains, with scattered plains and hills.

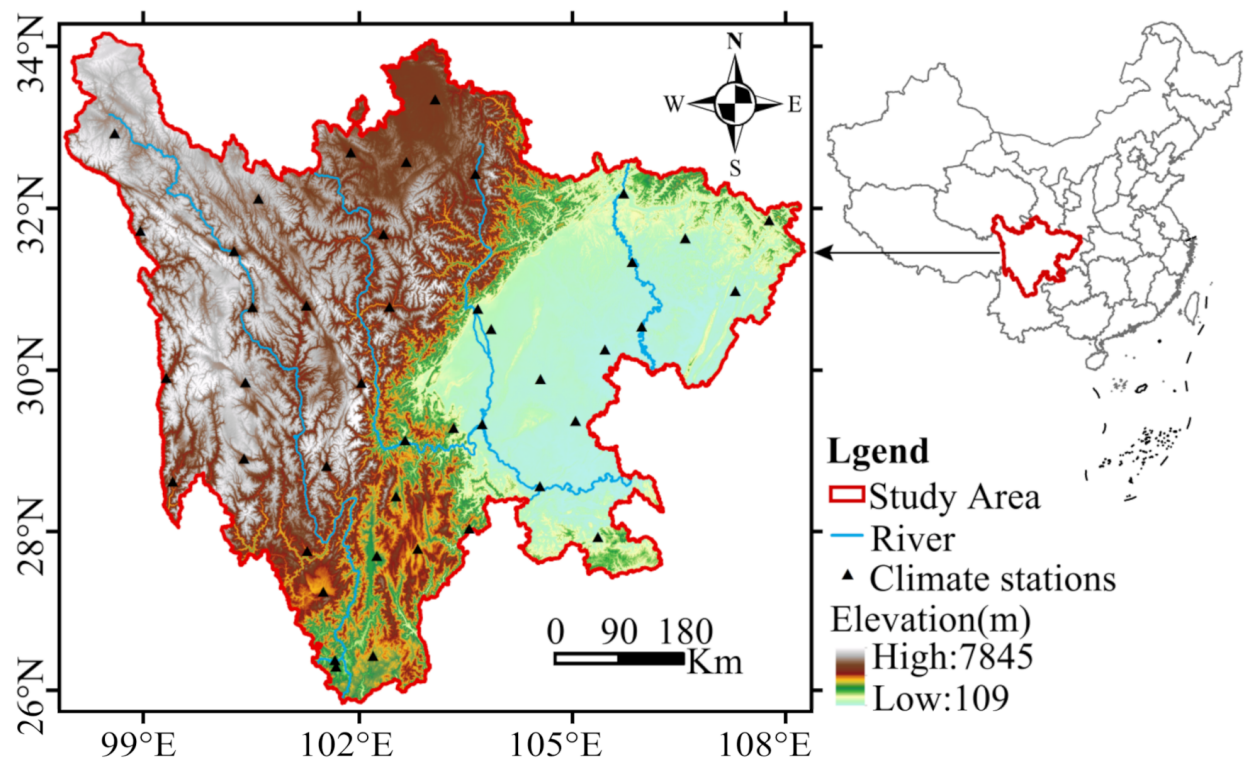

Figure 1. Location of the study area.

The climate of different geomorphic areas in Sichuan is obviously different. The climate of the western plateau and mountainous area changes significantly and vertically, with a predominantly cold-temperate climate, cold winters and cool summers, sufficient sunshine, an average annual temperature of 4 to $12{ }^{\circ} \mathrm{C}$, and annual precipitation of 500 to $900 \mathrm{~mm}$. The eastern basin has a subtropical monsoon climate with warm winters and hot summers, less sunshine, an annual average temperature of 16 to $18{ }^{\circ} \mathrm{C}$, and annual precipitation of 1000 to $1300 \mathrm{~mm}$. Due to the complex regional landform, fragile ecological environment and frequent occurrence of various meteorological disasters, coupled with the rapid expansion of construction land caused by rapid urbanization, the cultivated land is gradually decreasing, and the ecological security of cultivated land is under heavy pressure.

\subsection{Data}

The research data include remote sensing image data for extracting cultivated land information, DEM data for dividing geomorphic areas, and meteorological station data 
(Figure 2). The cultivated land data in 2000 and 2010 are mainly interpreted by $30 \mathrm{~m}$ multispectral images, including TM5, ETM +, and OLI multispectral images from Landsat and China's environmental disaster reduction satellite (HJ-1). The cultivated land data in 2020 were derived from 16 m resolution Gaofen-1 (GF-1) multispectral images. The principle of image selection is to select the multispectral images of the vegetation growth season within \pm 2 years of data production base year or update year, while ensuring that the images are cloudless (less cloud). The $30 \mathrm{~m}$ spatial resolution Digital Elevation Model (DEM) data comes from the geospatial data cloud mirror website of the computer network information center of the Chinese Academy of Sciences (http:/ / www.gscloud.cn/ accessed on 30 December 2021). The meteorological data comes from the monthly, seasonal, and annual series of temperature, precipitation, wind speed, and relative humidity data for 2000 to 2020 from 43 basic meteorological stations in Sichuan Province.

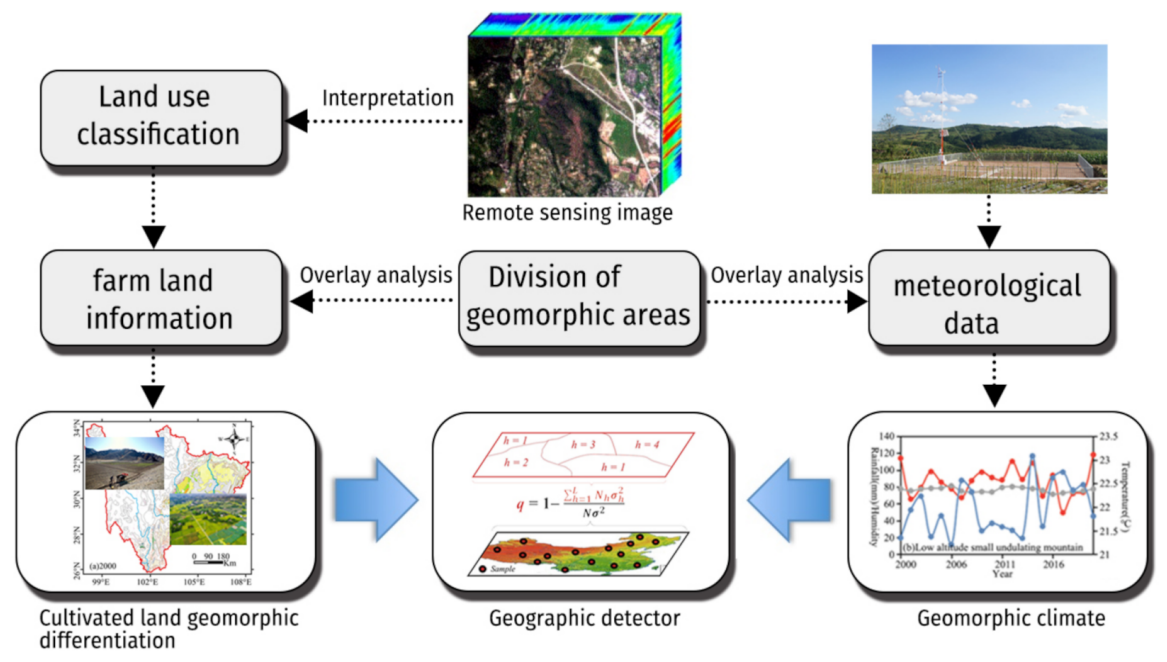

Figure 2. Research framework.

\subsection{Analysis Methods}

\subsubsection{Lorenz Curve and Gini Coefficient}

The spatial Lorenz curve and Gini coefficient are used to describe the spatial distribution of cultivated land. The Lorenz curve was proposed by M. Lorenz, an American economic statistician, to reflect the uniformity of regional income distribution. In this paper, the spatial Lorenz curve is drawn according to the cumulative percentage of cultivated land area proportion in each geomorphic area as the horizontal axis and the average cumulative percentage as the vertical axis. The closer the curve is to the absolute mean line, the more evenly distributed is cultivated land in the various areas.

The Gini coefficient is used to quantitatively reveal the average degree of distribution of various categories constituting the agricultural production space. Referring to the calculation method of the Gini coefficient in relevant studies, the calculation formula in this study is:

$$
G=\sum_{i=1}^{n-1}\left(M_{i} Q_{i+1}-M_{i+1} Q_{i}\right)
$$

where $G$ is the Gini coefficient of cultivated land geomorphic differentiation; $M_{i}$ is the cumulative percentage of cultivated land in a geomorphic area; and $Q_{i}$ is the cumulative percentage of the area of a geomorphic area in the total area of the study area. Since 37 geomorphic areas are defined in the study area, the value range of the integer $i$ is $0<i<37$. The smaller the Gini coefficient, the more evenly distributed the cultivated land in various geomorphic areas; conversely, the more unevenly distributed is the cultivated land [24]. 


\subsubsection{Getis-Ord Gi*}

The hot spot analysis method can reveal the spatial agglomeration characteristics of local areas and identify the spatial clustering of the high value (hot spot) and low value (cold spot) with statistical significance. The calculation formula shown in Getis-Ord $\mathrm{Gi}^{*}$ is as follows:

$$
G_{i}(d)=\frac{\sum_{j=1}^{n} w_{i j}(d) x_{j}}{\sum_{j=1}^{n} x_{j}}
$$

where $w_{i j}(d)$ is the weight matrix within the distance range $d, i \neq j . G_{i}(d)$ indicates the correlation degree between the statistics of geomorphic areas $i$ and adjacent geomorphic areas $i$ under the condition of distance weight. The formula for $Z\left(G_{i}\right)$ standardized treatment is:

$$
Z\left(G_{i}\right)=\frac{\left[G_{i}(d)\right]-E\left(G_{i}\right)}{\sqrt{\operatorname{VAR}\left(G_{i}\right)}}
$$

where $E\left(G_{i}\right)$ and $\operatorname{VAR}\left(G_{i}\right)$ represent the $G_{i}$ mathematical expectation and theoretical variance, respectively. If $Z\left(G_{i}\right)$ is positive and significant, more cultivated land is distributed in the geomorphic area around the surface geomorphic area $i$, then the geomorphic area $i$ belongs to the hot spot area. If $Z\left(G_{i}\right)$ is negative and significant, the increase of cultivated land around the geomorphic area $i$ is low, belonging to the cold spot area [25].

\subsubsection{Geographic Detector}

Geographic detectors are used to analyze the spatial correlation between the distribution of cultivated land and the driving factors. Geographic detectors mainly comprise risk detection, factor detection, ecological detection, and interactive detection. The formula of the model is as follows:

$$
q=1-\frac{1}{N \sigma^{2}} \sum_{i=1}^{L} N_{i} \sigma_{i}^{2}
$$

In the formula, $q$ is the spatial heterogeneity of a certain index; $q \in[0,1] ; N$ is the total sample number of the study area; $\sigma_{i}{ }^{2}$ is the variance of the index; $i=1,2, \ldots, L, i$ represents the partition, and $L$ represents the number of the partition. The size of $q$ reflects the degree of spatial differentiation; the larger the $q$ value, the stronger the heterogeneity of spatial stratification, and conversely, the stronger the randomness of spatial distribution. When $q=0$, this indicates no spatial heterogeneity in the research object; when $q=1$, this indicates perfect spatial heterogeneity [26].

\section{Results}

\subsection{Distribution of Cultivated Land in Different Geomorphic Areas}

In this study, based on the traditional basic geomorphic types of mountains and plains, the landforms are divided into seven categories according to geomorphic morphological characteristics and fluctuation height differences, and then divided into 37 geomorphic areas according to five-level altitude. The Lorenz curve is used to analyze the spatial distribution balance of cultivated land in different geomorphic areas. According to the calculation results for location entropy, the Lorenz curve of cultivated land distribution in different geomorphic areas is drawn. As shown in Figure 3, the Lorenz curve is far from the absolute average, and the Gini coefficient is 0.81897 , indicating that the spatial distribution of cultivated land is not balanced and has an obvious trend of agglomeration distribution. Further analysis shows that among the 37 geomorphic areas in the study area, 32 have cultivated land distribution. Among them, low altitude hills and low altitude small undulating mountains are the main geomorphic areas of cultivated land, and the average proportion of cultivated land over the years is $37.53 \%$ and $22.36 \%$, respectively. They are followed by the middle altitude middle undulating mountain $(9.03 \%)$, the middle high altitude large undulating mountain $(8.34 \%)$, the low altitude alluvial plain $(5.95 \%)$, the low altitude alluvial proluvial plain (3.34\%), the middle high altitude medium undulating 
mountain (3.02\%), the low altitude alluvial proluvial platform $(2.32 \%)$, the middle altitude large undulating mountain (1.58\%), the low altitude medium undulating mountain (1.21\%) and the high altitude large undulating mountain (1.25\%), and other geomorphic areas. However, the average cultivated land area in the other 21 geomorphic areas is less than $1 \%$ over the years. Generally, cultivated land is mainly concentrated and distributed in middle and low altitude, medium and small undulating hills and mountains, and secondarily concentrated and distributed in low altitude alluvial, proluvial plains and platforms.

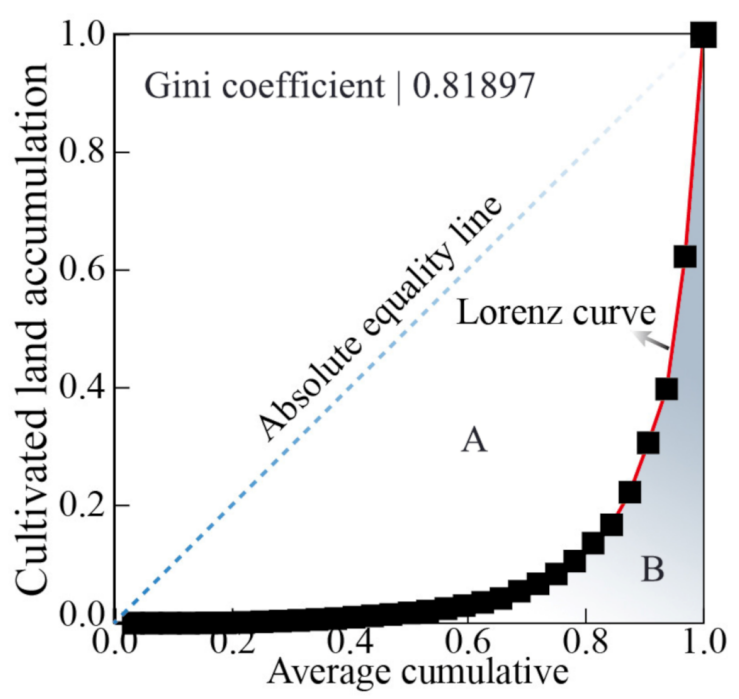

Figure 3. Lorentz curve of cultivated land geomorphic differentiation.

\subsection{Spatial Correlation of Cultivated Land Distribution in Different Geomorphic Areas}

The global autocorrelation analysis by Geoda showed that the Moran's I index of cultivated land area in 2020 is 0.466 , and the $Z$ value is 10.94 , with $p=0.001$ by significance test, showing a positive spatial correlation. The results of local spatial autocorrelation analysis showed that the geomorphic differentiation and clustering characteristics of cultivated land are not significant in agroclimatic areas such as the forest and pastoral areas in the mountains and valleys of Western Sichuan, the pastoral areas in the sub cold zone of Northwest Sichuan Plateau and the pastoral areas in the sub cold zone of Western Sichuan Plateau. In the hilly warm temperate forest, pastoral and agricultural areas in eastern Sichuan (Figure 4), high-high aggregation classes are the largest, and low-high aggregation classes are few. The high-high aggregation classes are mainly distributed in areas with similar natural conditions, such as Suining, Nanchong, Guang'an, and Neijiang. The main distribution areas of low-high aggregation classes are located in Yibin, Luzhou, and other areas. This is because the topographic conditions in these areas change greatly, including low altitude and low undulating hills and mountains where cultivated land is mainly distributed, and medium and high altitude and large undulating mountains where there is less cultivated land, resulting in local spatial heterogeneity of cultivated land geomorphic differentiation. 


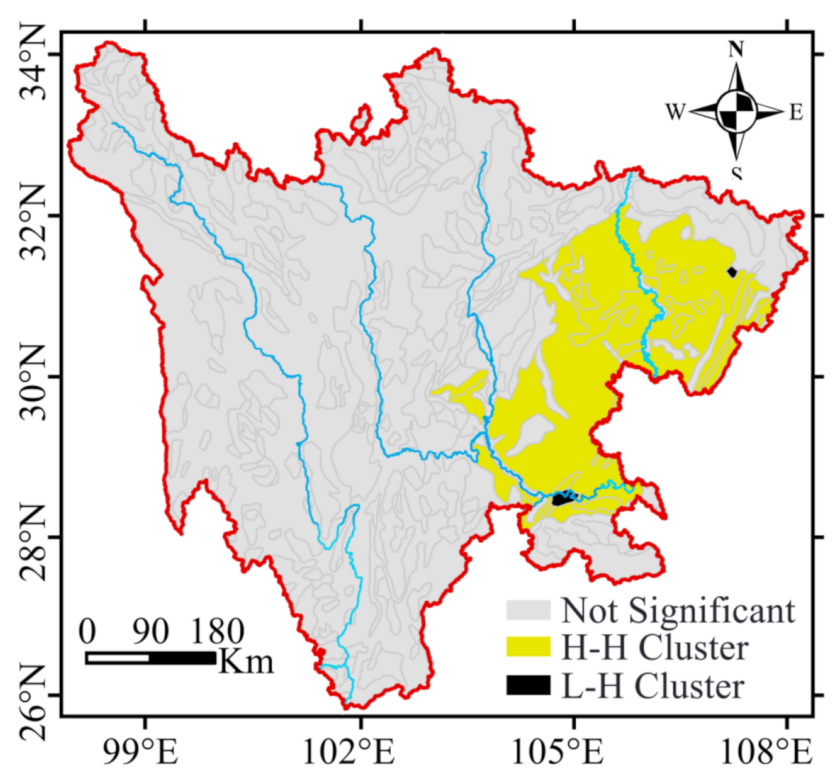

Figure 4. Clustering characteristics of cultivated land geomorphic differentiation.

\subsection{Temporal and Spatial Changes of Cultivated Land in Different Geomorphic Areas}

From 2000 to 2010, the cultivated land in the medium and high-altitude alluvial plain and high-altitude alluvial plain changed dramatically (Figure 5), and the cultivated land area increased by $288.74 \%$ and $282.29 \%$, respectively. In other geomorphic areas, the cultivated land area of the high-altitude alluvial proluvial platform decreased by $30.22 \%$, the cultivated land area of the high-altitude ice water sedimentary plain increased by $25.36 \%$, the cultivated land area of large undulating mountains increased by $10.44 \%$, and the cultivated land area of the medium and high-altitude alluvial proluvial plain decreased by $9.78 \%$. In the geomorphic areas with high cultivated land area distribution, such as low-altitude hills, low-altitude small undulating mountains, middle altitude medium undulating mountains, and other geomorphic areas, the change of cultivated land area is relatively small, increasing by $0.34 \%, 0.52 \%$, and $2.43 \%$, respectively. In addition, in the geomorphic areas with high cultivated land area, such as the low-altitude alluvial plain and low-altitude alluvial proluvial plain, the cultivated land area decreased by $1.15 \%$ and $1.14 \%$, respectively. In general, from 2000 to 2010, the distribution scale of cultivated land in the geomorphic areas of the study area mainly increased, and a small-scale increase occurred, with the pattern that small and medium-sized rolling hills and mountains at middle and low altitudes were the main distribution geomorphic areas of cultivated land. However, in the geomorphic areas such as the low-altitude alluvial plain and low-altitude alluvial proluvial plain where the distribution of cultivated land is mainly concentrated, there is a small-scale decline in cultivated land. 


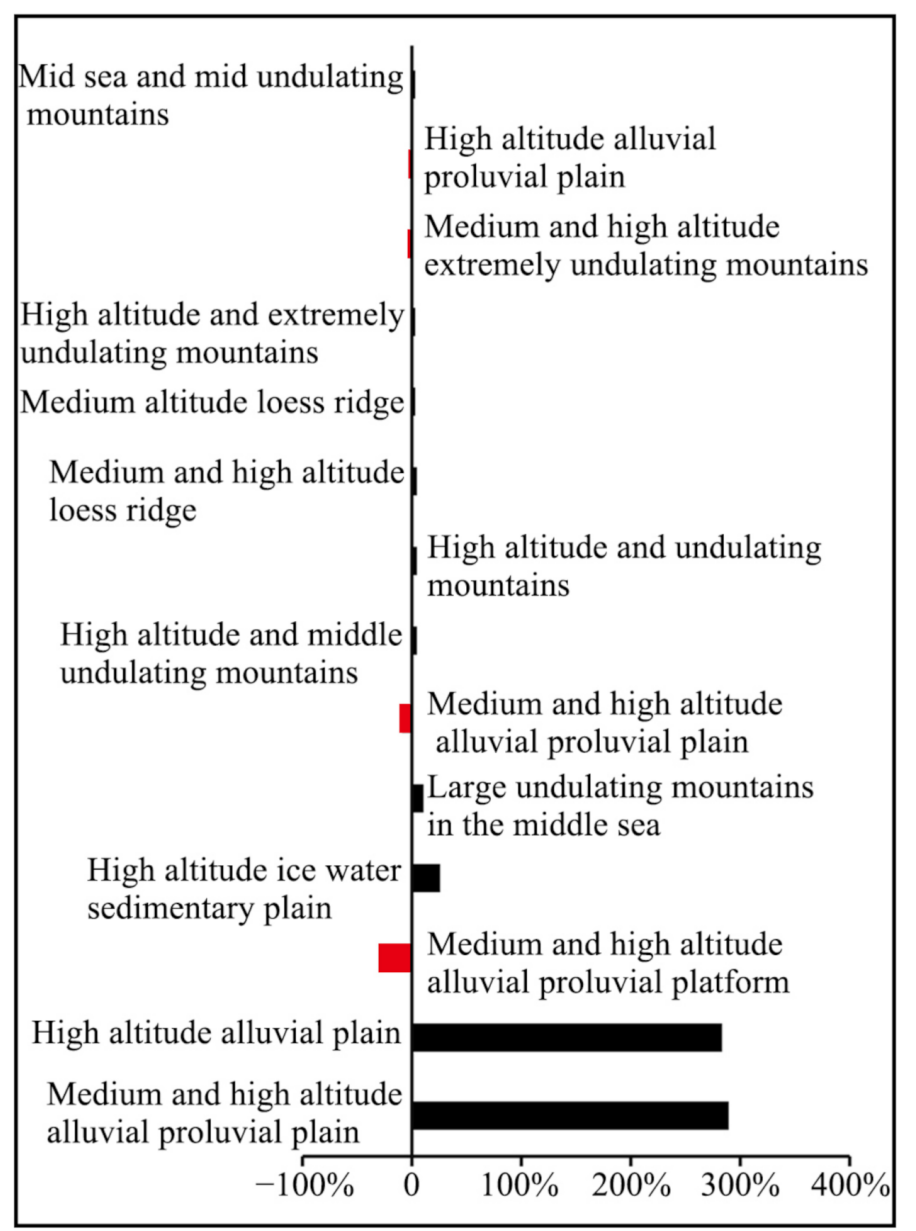

Figure 5. Top 14 geomorphic areas of cultivated land area change from 2000 to 2010.

From 2010-2020, compared with 2000-2010, the cultivated land changed greatly, and the total amount of cultivated land decreased. During this period, except for the increase in cultivated land area in geomorphic areas such as the high-altitude ice water sedimentary plain, high-altitude extremely undulating mountain, medium and high-altitude alluvial proluvial platform, medium and high-altitude alluvial proluvial lacustrine platform, medium and high-altitude denudation plain, high-altitude greatly undulating mountain and medium and high-altitude extremely undulating mountain (Figure 6), the cultivated land area of the other 25 geomorphic areas decreased. There was a small-scale decline in the geomorphic areas such as low-altitude hills, low-altitude small undulating mountains and middle altitude medium undulating mountains with more cultivated land distribution, and the cultivated land area decreased by $1.89 \%, 1.74 \%$, and $2 \%$, respectively. Moreover, the proportion of cultivated land decreased significantly in geomorphic areas such as low-altitude alluvial plain, low-altitude alluvial proluvial plain, and low-altitude alluvial proluvial platform. Among these, the cultivated land of the low-altitude alluvial plain decreased by $12.57 \%$, the cultivated land of the low-altitude alluvial proluvial plain decreased by $11.76 \%$, and the cultivated land of the low-altitude alluvial proluvial platform decreased by $10.79 \%$. This shows that the total amount of cultivated land in the study area decreased from 2010 to 2020. The spatial distribution of cultivated land scale showed that it decreased continuously in low-altitude alluvial proluvial plains, platforms and other low-ecological risk geomorphic areas, while the cultivated land scale increased in high-altitude undulating mountains, medium and high-altitude undulating mountains and other high-ecological risk geomorphic areas (Figure 7). 


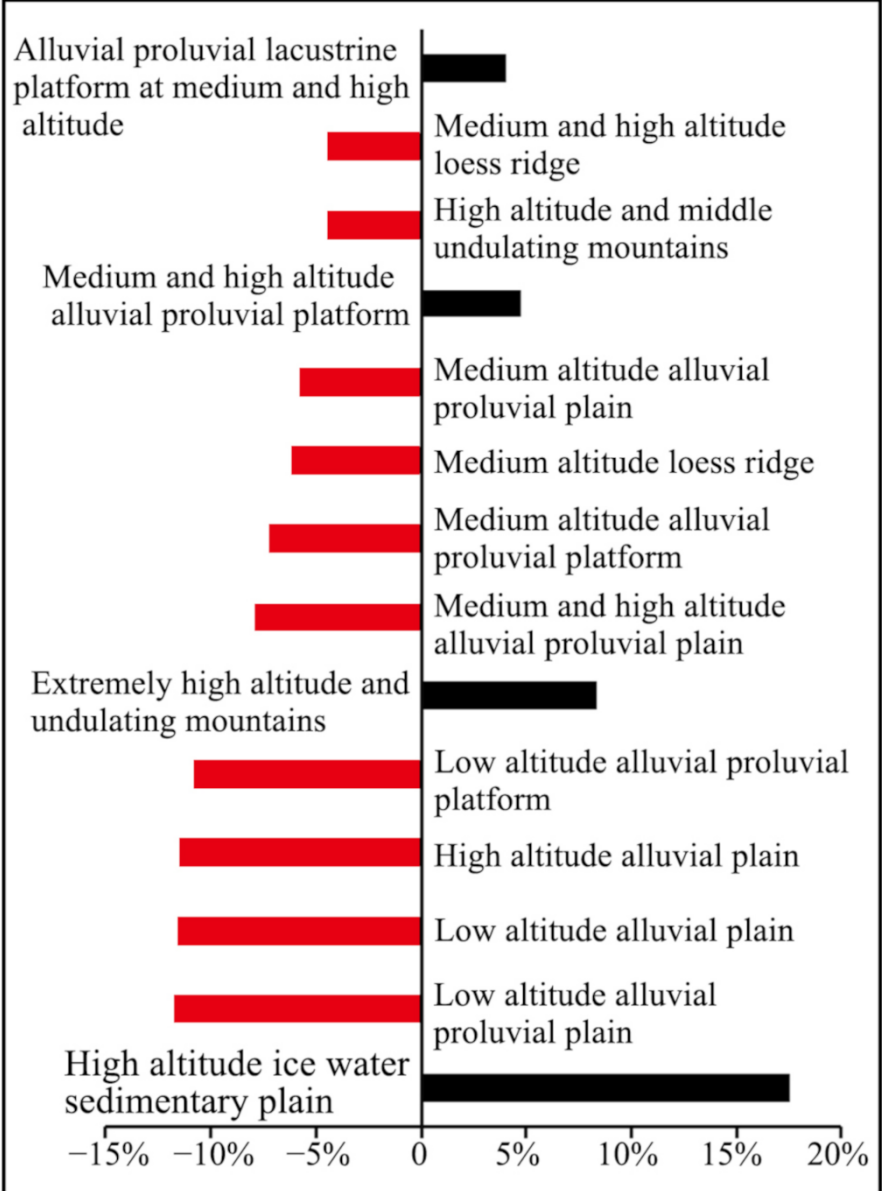

Figure 6. Top 14 geomorphic areas of cultivated land area change from 2010 to 2020.

\subsection{Cold Hot Spot Model of Temporal and Spatial Differentiation of Cultivated Land Landform}

In order to further identify the temporal and spatial patterns of cultivated land geomorphic differentiation, the Getis-Ord $\mathrm{Gi}^{*}$ index was first calculated based on the change rate of cultivated land area in each physiognomy area during 2000-2010 and 2010-2020, and GI_Bin interval was used to determine the spatial agglomeration characteristics of cold and hot spots. As shown in Figure 8, cultivated land changes in different geomorphic areas from 2000-2010 mainly show four modes: primary hot spot, secondary hot spot, tertiary hot spot and insignificant, and the primary hot spot area is the main one. Meanwhile, the hot spots are distributed in two clusters in the north and south of Sichuan Basin. Among them, the first-class hot spots are distributed in the hilly and mountainous areas with medium and low altitude and medium and small fluctuation in the Jialing River Basin in the north of the basin, as well as the hilly and mountainous areas with medium and low altitude and medium and small fluctuation in the Minjiang River Basin and the mainstream of the Yangtze River in the south of the basin. From 2010 to 2020, the change of cultivated land in different geomorphic areas has a variety of cold and hot spot modes, mainly in three-level hot spots, which are concentrated in low-altitude hills, mountains, and alluvial plains in the middle of the basin. In contrast to 2000-2010, the primary hot spots in the north and south of the basin in 2000-2010 will gradually become cold spots from 2010-2020. Combined with the quantitative change characteristics of cultivated land in the geomorphic area, it is clear that the characteristics of cultivated land change and hot spots in the study area have a significant evolution trend, from new cultivated land in the north and south of the basin to reduced cultivated land in the middle of the basin, in the last two decades. 

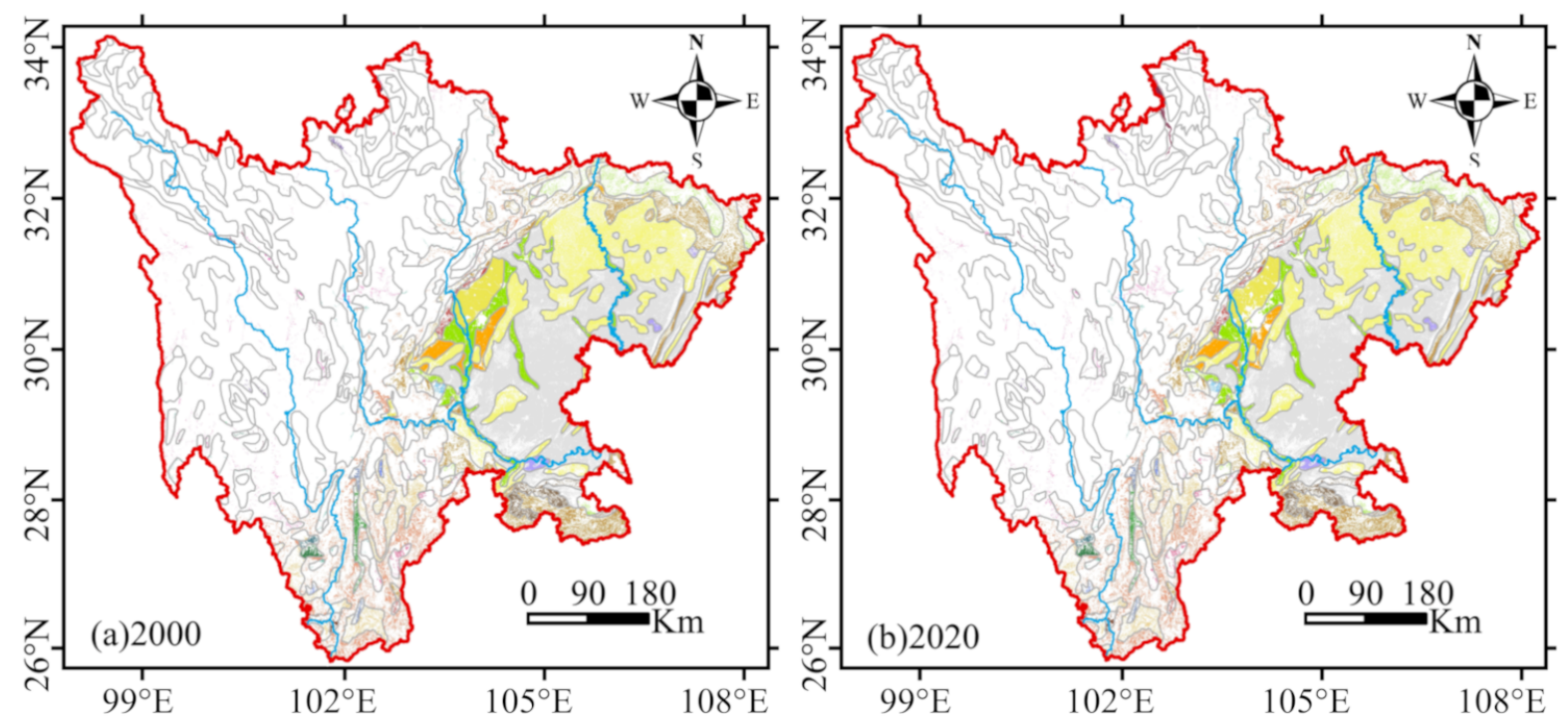

High altitude and undulating mountains $(4.74 \%)$

Low altitude medium undulating mountains $(-1.27 \%)$

Large undulating mountains in the middle sea( $(9.48 \%)$

Medium and high altitude rolling mountains $(-0.53 \%)$

Medium high altitude and medium undulating mountains $(-0.20 \%)$

Low altitude alluvial proluvial plain(-12.77\%) Mid sea and mid undulating mountains $(0.38 \%)$

Low altitude alluvial plain $(-12.57 \%)$

Low altitude small undulating mountain $(-1.22 \%)$

Low altitude alluvial proluvial platform $(-10.97 \%)$

Figure 7. Cultivated land distribution changes in different geomorphic areas from 2000 to 2020.
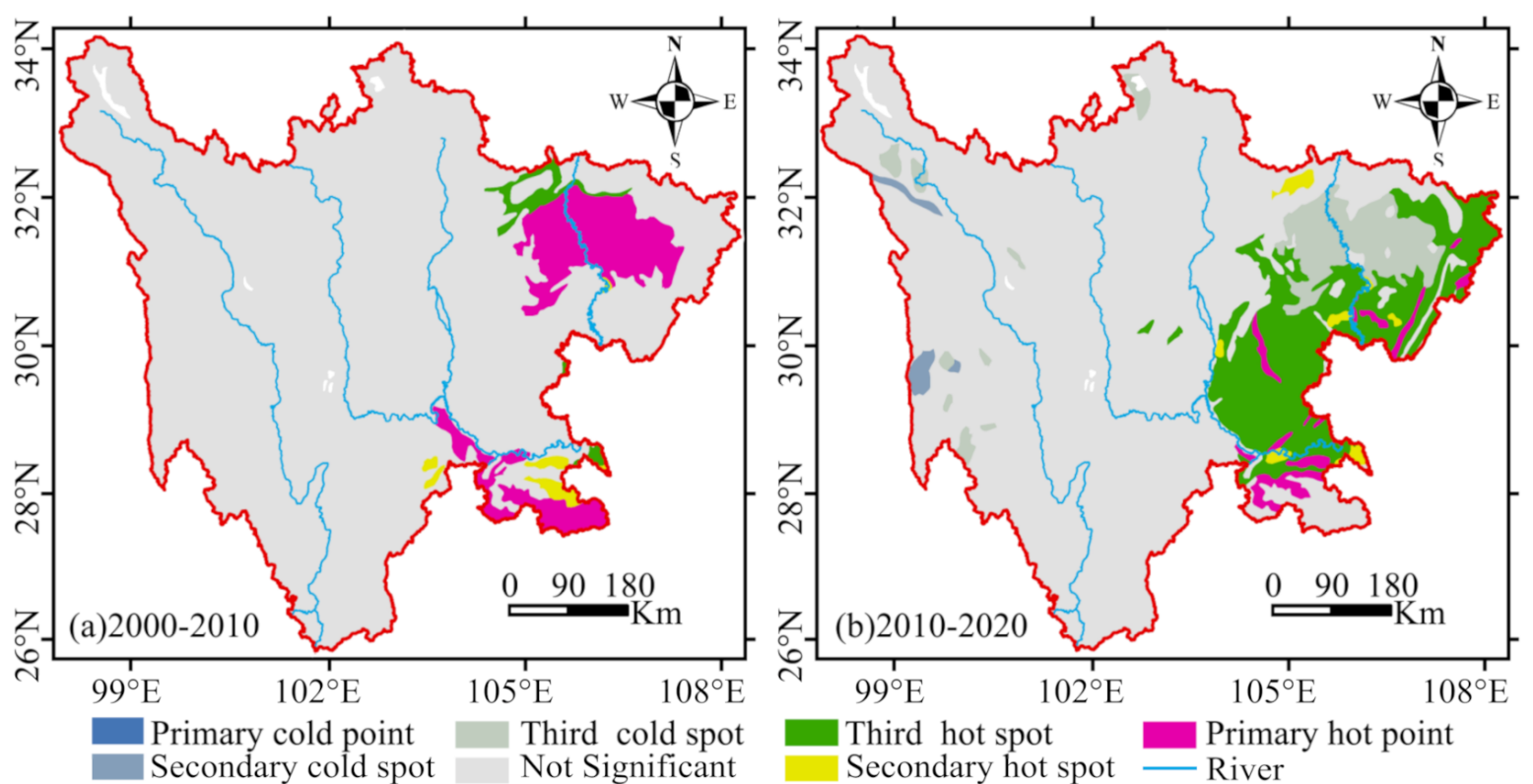

Figure 8. Identification of hot spots of cultivated land area change from 2000-2020. 


\subsection{Climate Response of Cultivated Land Geomorphic Differentiation}

\subsubsection{Meteorological Change Characteristics of Each Geomorphic Area}

In order to describe the response law of cultivated land distribution to meteorological factors in different geomorphic areas, 43 meteorological stations were merged into the geomorphic area, and the meteorological factors of each geomorphic area were calculated. As shown in Figure 9, according to the distribution and changes of cultivated land in the past 20 years, eight typical geomorphic areas were selected. The time-series data from 2000-2020 are taken as the abscissa to obtain the multi-year meteorological changes of different geomorphic areas with the multi-year average temperature, average rainfall and average humidity of different geomorphic areas as the ordinate. Taking 2020 as an example, the highest average temperature in the middle altitude and middle undulating mountains is $23.32{ }^{\circ} \mathrm{C}$, while that in the middle and high altitude alluvial plain is only $2.79{ }^{\circ} \mathrm{C}$. The low altitude alluvial plain with the highest average rainfall has an average annual rainfall of $123.59 \mathrm{~mm}$, while the high altitude undulating mountain has an average annual rainfall of $37.35 \mathrm{~mm}$. There is also a difference of 40.61 units between the geomorphic area with the highest relative humidity and the geomorphic area with the lowest relative humidity. Obviously, there are significant differences in temperature, precipitation and humidity in different geomorphic areas. Specifically, in terms of the change rates of meteorological factors over the years, the lowest rate of temperature change is in the low altitude hilly area $(-111.1 \%)$, the highest rate of temperature change is in the high altitude alluvial proluvial plain $(-10.7 \%)$, and the highest rate of average temperature change is in the medium and high altitude alluvial plain $(-55.8 \%)$. In addition, the highest rate of rainfall change is in the medium altitude and medium undulating mountain (133.1\%), the highest change rate of minimum rainfall is in the medium and high altitude alluvial plain $(2900 \%)$, the highest change rate of average rainfall is in the low altitude alluvial plain $(-37.7 \%)$, the highest change rate of average wind speed is in the low altitude hills $(-62.1 \%)$, and the highest change rate of average humidity is in the high altitude undulating mountains (20.0\%). It can be seen that the meteorological factors in various areas show obvious fluctuations in temporal and spatial series.

The response law of cultivated land geomorphic differentiation to meteorological factors was further analyzed, and meteorological index data such as maximum temperature, minimum temperature, average temperature, maximum rainfall, minimum rainfall, average rainfall, average humidity and average wind speed obtained for many years. The influence of meteorological factors on cultivated land geomorphic differentiation was analyzed from two aspects of interactive detection. The factor detector calculates the PD value ranking of meteorological factors in each geomorphic area; by comparing the PD value of a single meteorological factor with the PD value of two factors, the interaction detector can determine whether the meteorological factors have an independent or interaction effect on cultivated land geomorphic differentiation, and whether the interaction is synergistic or inhibitory. 

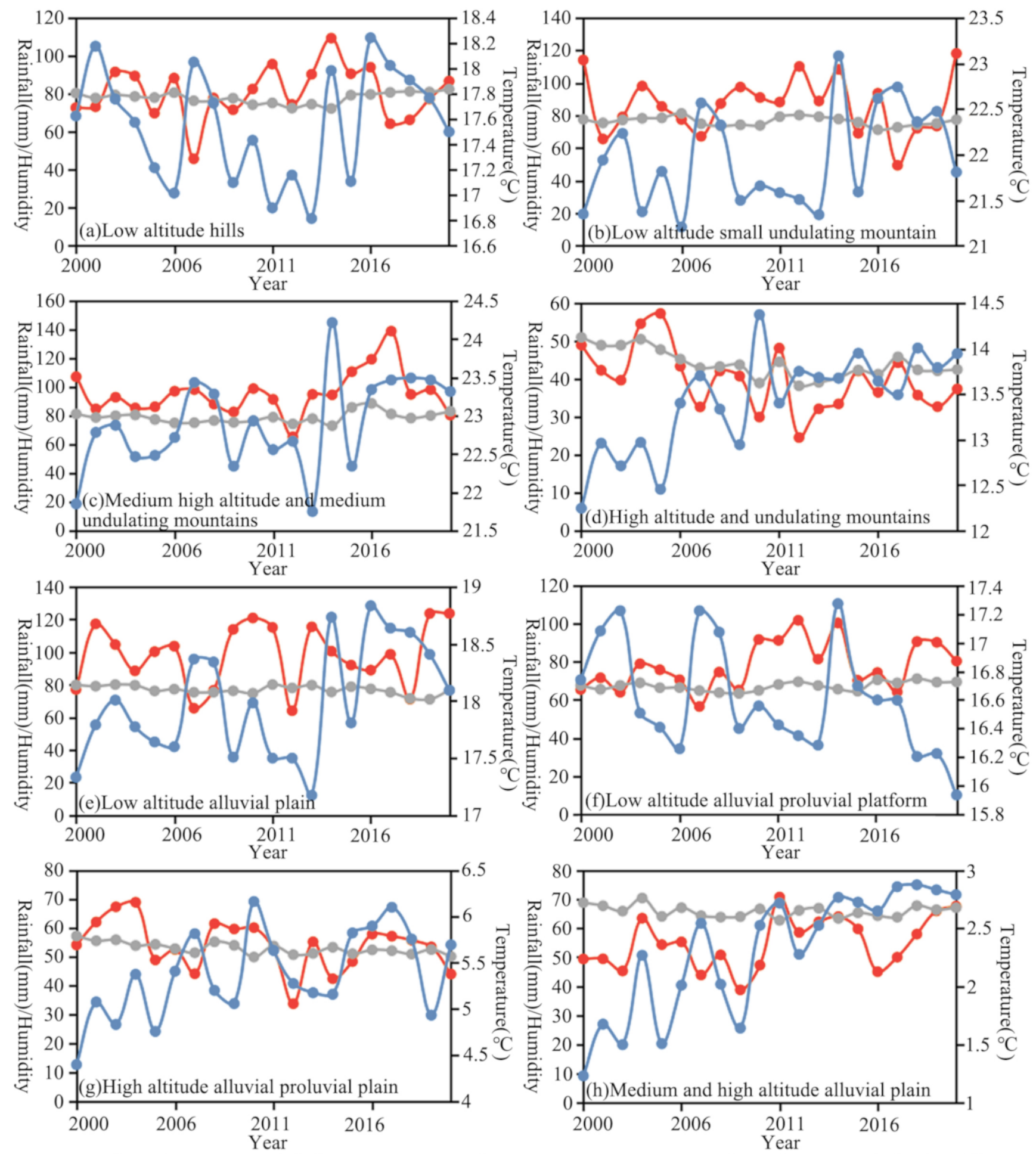

$\_$Annual average precipitation $\longrightarrow$ Annual average temperature $\longrightarrow$ Annual average relative humidity

Figure 9. Changes in annual average temperature, precipitation and relative humidity in typical geomorphic areas.

\subsubsection{Single Factor Attribution of Cultivated Land Geomorphic Differentiation}

In the whole study area, the highest temperature explained the most spatial heterogeneity of cultivated land at $65.5 \%$ (significance level of $99 \%$ ). This was followed by the lowest temperature, average temperature and average relative humidity at $57.0 \%$ (significance level 95\%), 52.8\% (significance level 95\%) and 50.5\% (significance level 95\%), 
respectively. The average rainfall, average wind speed, minimum rainfall and maximum rainfall have weak explanatory ability for the spatial heterogeneity of cultivated land, at 40.6\% (significance level 95\%), 40.5\% (significance level 95\%), 38.8\% (significance level 95\%) and $17.8 \%$, respectively.

In different geomorphic divisions, there are significant differences in the category and degree of influence of meteorological factors affecting the spatial distribution of cultivated land (Figure 10). For example, the minimum temperature has a weak explanatory power of $29.1 \%$ on the distribution of cultivated land in low altitude small undulating mountains, while it is as high as $78.8 \%$ in high altitude alluvial proluvial plains. The explanatory power of the maximum rainfall on the distribution of cultivated land in the alluvial proluvial platform at low altitude is $22.8 \%$, while this is $75.9 \%$ and $72.5 \%$ for the small undulating mountain at low altitude and the medium undulating mountain at medium altitude, respectively. In terms of various geomorphic areas, low altitude hilly areas are most affected by minimum rainfall, low altitude small undulating mountains are most affected by maximum rainfall, middle altitude medium undulating mountains are most affected by average wind speed, high altitude large undulating mountains are most affected by average relative humidity, and low altitude alluvial plains are most affected by average temperature Low altitude alluvial proluvial platform is most affected by average relative humidity, high altitude alluvial proluvial plain is most affected by average temperature, and medium and high altitude alluvial plain is most affected by average temperature. In general, the distribution of cultivated land in medium and high altitude geomorphic areas is greatly affected by temperature, while the distribution of cultivated land in low altitude geomorphic areas is more affected by rainfall.

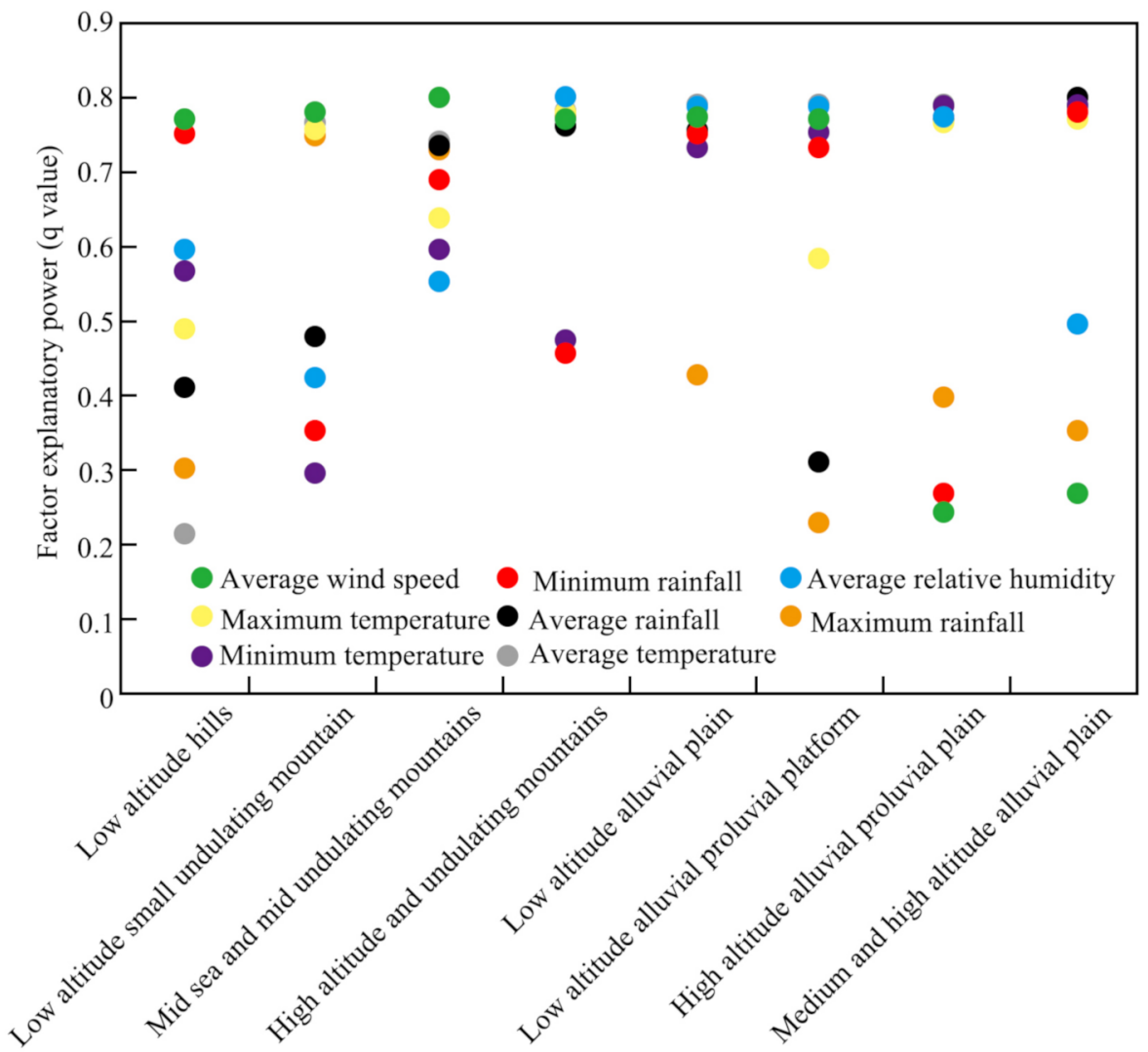

Figure 10. Influence of meteorological factors on cultivated land differentiation in different geomorphic areas. 


\subsubsection{Interaction of Influencing Factors of Cultivated Land Geomorphic Differentiation}

Through the comprehensive effect of changes in temperature and precipitation, climate changes ecological system elements such as light, temperature, water, soil, gas and biomass, and then has an impact on the planting system, pest control, agricultural production potential and agricultural management, thus affecting the distribution of cultivated land for planting agricultural economic crops.The multi-factor interaction of cultivated land geomorphic differentiation was carried out using the interactive detection module of the geographic detector. The calculation results show a wide range in the two factors increasing the effect among climatic factors in each physiognomic area, and most of the factors experience nonlinear enhancement after this interaction. The main interaction factors of cultivated land distribution in different geomorphic areas are different. As shown in Table 1, the distribution of cultivated land in low altitude areas is most affected by extreme precipitation factors such as maximum rainfall and minimum rainfall, while the low altitude small undulating mountains are most affected by extreme temperatures such as maximum temperature and minimum temperature. The undulating mountains in the middle sea are more affected by the combination of climatic factors such as average temperature, average rainfall and average humidity. High altitude and large fluctuation mountainous areas have a higher impact on the factor combination of average temperature and average relative humidity. The low altitude alluvial plain and low altitude alluvial proluvial platform are more affected by the combination of extreme temperature and extreme rainfall. The high altitude alluvial proluvial plain is most affected by extreme temperature factors. The medium and high altitude alluvial plain is more affected by the combination of minimum temperature and average temperature.

Table 1. Interaction detection of influencing factors on cultivated land spatial distribution in different geomorphic areas.

\begin{tabular}{|c|c|c|c|}
\hline \multirow{2}{*}{$\begin{array}{c}\text { Typical Geomorphic Area } \\
\text { Low altitude hills }\end{array}$} & \multicolumn{3}{|c|}{ Interaction of Main Meteorological Factors } \\
\hline & $\begin{array}{l}\text { Maximum rainfall } \cap \\
\text { minimum rainfall }\end{array}$ & $\begin{array}{l}\text { Maximum temperature } \cap \\
\text { minimum rainfall }\end{array}$ & $\begin{array}{l}\text { Maximum temperature } \cap \\
\text { average wind speed }\end{array}$ \\
\hline $\begin{array}{l}\text { Low altitude small undulating } \\
\text { mountain }\end{array}$ & $\begin{array}{l}\text { Maximum temperature } \cap \\
\text { minimum temperature }\end{array}$ & $\begin{array}{l}\text { Maximum temperature } \cap \\
\text { average relative humidity }\end{array}$ & $\begin{array}{l}\text { Maximum temperature } \cap \\
\text { average rainfall }\end{array}$ \\
\hline $\begin{array}{l}\text { Mid sea and mid undulating } \\
\text { mountains }\end{array}$ & $\begin{array}{c}\text { Minimum temperature } \cap \\
\text { average rainfall }\end{array}$ & $\begin{array}{l}\text { Average rainfall } \cap \text { average } \\
\text { relative humidity }\end{array}$ & $\begin{array}{l}\text { Average wind speed } \cap \\
\text { average relative humidity }\end{array}$ \\
\hline $\begin{array}{l}\text { High altitude and undulating } \\
\text { mountains }\end{array}$ & $\begin{array}{l}\text { Average temperature } \cap \\
\text { average relative humidity }\end{array}$ & $\begin{array}{l}\text { Minimum temperature } \cap \\
\text { average wind speed }\end{array}$ & $\begin{array}{l}\text { Average rainfall } \cap \text { average } \\
\text { relative humidity }\end{array}$ \\
\hline Low altitude alluvial plain & $\begin{array}{l}\text { Maximum temperature } \cap \\
\text { minimum rainfall }\end{array}$ & $\begin{array}{c}\text { Maximum temperature } \cap \\
\text { average rainfall }\end{array}$ & $\begin{array}{l}\text { Maximum temperature } \cap \\
\text { average wind speed }\end{array}$ \\
\hline $\begin{array}{l}\text { Low altitude alluvial } \\
\text { proluvial platform }\end{array}$ & $\begin{array}{l}\text { Minimum temperature } \cap \\
\text { maximum rainfall }\end{array}$ & $\begin{array}{l}\text { Maximum temperature } \cap \\
\text { minimum temperature }\end{array}$ & $\begin{array}{l}\text { Maximum rainfall } \cap \\
\text { minimum rainfall }\end{array}$ \\
\hline $\begin{array}{l}\text { High altitude alluvial } \\
\text { proluvial plain }\end{array}$ & $\begin{array}{l}\text { Minimum temperature } \cap \\
\text { maximum temperature }\end{array}$ & $\begin{array}{c}\text { Minimum temperature } \cap \\
\text { average rainfall }\end{array}$ & $\begin{array}{l}\text { Maximum temperature } \cap \\
\text { average temperature }\end{array}$ \\
\hline $\begin{array}{l}\text { Medium and high altitude } \\
\text { alluvial plain }\end{array}$ & $\begin{array}{l}\text { Minimum temperature } \cap \\
\text { average temperature }\end{array}$ & $\begin{array}{l}\text { Maximum temperature } \cap \\
\text { average temperature }\end{array}$ & $\begin{array}{l}\text { Average temperature } \cap \\
\text { maximum rainfall }\end{array}$ \\
\hline
\end{tabular}

\section{Discussion}

\subsection{Characteristics of Cultivated Land Geomorphic Differentiation and Temporal and Spatial Transfer}

According to the analysis results of cultivated land distribution in the study area, cultivated land is mainly distributed in low-altitude hills, low-altitude small undulating mountains, and low-altitude alluvial, and proluvial plains in the Sichuan Basin. This is consistent with the research results of Li and Wang [27] on the distribution of cultivated land in Sichuan Province. This is because the Sichuan Basin is low and flat, and belongs to a subtropical monsoon climate area with superior hydrothermal conditions. The soils are mainly paddy soil, alluvial soil and purple soil, which are fertile. A high economic level and advanced agricultural production technology nourish this vast and fertile cultivated land, 
which is the main crop-producing area of the province. However, there is less distribution of cultivated land in the forest-pastoral agricultural areas in the mountains and valleys of Western Sichuan, the pastoral areas in the sub-cold zone of Northwest Sichuan Plateau, and the pastoral areas in the sub cold zone of Western Sichuan Plateau, which is related to the complex landform on the eastern edge of the Qinghai Tibet Plateau. The altitude is more than $4000 \mathrm{~m}$, the terrain is high and steep, the hydrothermal conditions are poor, and the highlands and mountains are covered with red soil, yellow-red soil and alpine cold desert soil, most of which are not conducive to crop growth. Therefore, the distribution of cultivated land is limited. At the same time, the study also found that there are some areas with large spatial heterogeneity of cultivated land distribution. These areas are located in the mountains of Southwest Sichuan, where the geomorphic conditions change greatly. Moreover, there are low altitude areas suitable for crop growth and medium and high altitude undulating geomorphic areas unfavorable to crop growth.

In addition, according to the analysis results of temporal and spatial changes of cultivated land from 2000-2020, the change in cultivated land in geomorphic areas generally shows that the scale of cultivated land decreases in alluvial proluvial plain and platform medium geomorphic areas at low altitude, while the scale of cultivated land increases in high-altitude undulating mountains, medium and high-altitude extremely undulating mountains and other geomorphic areas. This study also analyzed the spatial location of these geomorphic areas with large changes in cultivated land, and found that the cultivated land in Northwest Sichuan Plateau and central Sichuan Basin experienced great changes. This result is also consistent with the research of Wang and Yang [28]. The increase of cultivated land in Northwest Sichuan Plateau shows that the agricultural development of this area has been improved after a series of policies adopted by the government. The decrease of cultivated land in the middle of Sichuan Basin is closely related to the rapid urbanization process in this area. In the process of urbanization, the demand for land points to cultivated land, forcing the conversion of cultivated land into non-agricultural use. Urbanization has become an important reason for the reduction in cultivated land area.

\subsection{Complex Effects of Climatic Factors on Temporal and Spatial Differentiation of Cultivated Land Landform}

This study also discusses the impact of climatic factors on cultivated land distribution. Different from previous studies, it focuses on the geomorphic differences in the impact of climatic factors on cultivated land distribution. The results also show that the climatic factors affecting the distribution of cultivated land are different in different geomorphic areas, and the combination of different climatic factors also has obvious geomorphic differentiation characteristics. This research result is closely related to the complex geomorphic characteristics of the study area. Most of the cultivated land in the northwest of Sichuan Province is dry land, while paddy fields are mainly distributed in the southeast, which is consistent with the precipitation distribution characteristics of Sichuan Province, indicating that the regional climate conditions have a great impact on the change in cultivated land. In addition, in terms of local geomorphic areas, Northwest Sichuan is mainly characterized by plateau and mountainous climate with low temperature, high frost and snow, and scarce rain, and these harsh natural conditions limit the growth of most crops. The latitude of the mountainous areas in Southwest Sichuan and the mountainous areas around the basin (southern region) is low, and mainly shows subtropical humid and semi-humid climates. The influence of hydrothermal conditions on cultivated land is stable. Therefore, the distribution of cultivated land in different geomorphic areas will be affected by different climatic factors.

\subsection{Adaptive Strategies of Agricultural Production in Different Geomorphic Areas}

To adapt to future climatic changes and reduce their impact on grain production, the following are suggested: (1) Select and cultivate crop varieties with characteristics of disease and insect resistance, high temperature resistance and water saving, and improve 
field management measures to improve the utilization efficiency of water and fertilizer. (2) Because the maximum temperature and minimum temperature are of great significance in the development and growth of plant life cycle [29], the crop planting system, crop layout and variety layout should be adjusted according to the climatic change trend in different geomorphic areas. In the mountainous areas of Southwest Sichuan with low and flat terrain and good irrigation conditions and the mountainous areas around the basin, the wheat (oil, potato-rice paddy dry rotation double cropping system is mainly used, while the wheat (oil), jade-Sweet Potato (bean) dry triple cropping system is mainly used in the northwest of Sichuan without a water source guarantee. (3) Improve the monitoring and early warning mechanism for meteorological disasters, establish prediction, monitoring and monitoring networks, and strengthen the construction of agricultural infrastructure. For example, establish a water-saving production system in Alpine geomorphic areas with poor hydrothermal conditions, and strengthen the construction of water storage and flood discharge projects in low altitude plain areas to enhance the ability to resist drought, flood control and extreme climate events.

\section{Conclusions}

Based on the Gini coefficient, spatial autocorrelation analysis and geographic detector, this study analyzed the distribution and evolution of cultivated land and its response to climatic factors in Sichuan Province at the scale of geomorphic area. The results show that: (1) low altitude hills and low altitude small undulating mountains are the main geomorphic areas of cultivated land; (2) in the low altitude plain landform area, the scale of cultivated land continues to decline, while in the high altitude undulating mountainous landform area, the scale of cultivated land has increased; (3) from 2000-2020, the new cultivated land in the north and south of the basin gradually changed to the level of the reduced cultivated land in the middle of the basin; (4) in the whole study area, the highest temperature has the strongest ability to explain the spatial heterogeneity of cultivated land. The two-factor interaction effects of climatic factors on cultivated land distribution in different geomorphic areas are different.

The impact of climatic changes on global environmental change and sustainable development has attracted increasing attention. Countries all over the world are seeking cooperation and active response to avoid the adverse impact of climatic changes on agricultural production and food security. Taking Sichuan Province of China as an example, this study reveals the climatic response characteristics of cultivated land change in complex landform areas, and puts forward the formulation of long-term strategies in complex landform areas to adapt agricultural production to climatic changes and reduce the direct negative impact of environmental change on agricultural production as much as possible.

Author Contributions: Conceptualization, Q.X. and H.Y.; methodology, Q.X.; software, Q.X.; validation, Q.X., H.Y. and H.H.; formal analysis, Q.X.; investigation, Q.X.; resources, X.X.; data curation, Q.X.; writing—original draft preparation, Q.X.; writing—review and editing, Q.X.; visualization, Q.X.; supervision, X.X.; project administration, H.Y.; funding acquisition, H.Y. All authors have read and agreed to the published version of the manuscript.

Funding: This research was funded by the National Natural Science Fundation of China (grant no. 41971226; 41871357) and the Strategic Priority Research Program of the Chinese Academy of Sciences (XDA19030303, XDA28110503).

Institutional Review Board Statement: Not applicable.

Informed Consent Statement: Not applicable.

Data Availability Statement: The new data created in this study are available on request.

Acknowledgments: The authors would like to thank the anonymous reviewers for their comments and suggestions which contributed to the further improvement of this paper.

Conflicts of Interest: The authors have declared no conflict of interest. 


\section{References}

1. Ramankutty, N.; Foley, J.A.; Norman, J.; McSweeney, K. The global distribution of cultivable lands: Current patterns and sensitivity to possible climate change. Glob. Ecol. Biogeogr. 2002, 11, 377-392. [CrossRef]

2. Hazell, P.; Wood, S. Drivers of change in global agriculture. Philos. Trans. R. Soc. B Biol. Sci. 2008, 363, 495-515. [CrossRef]

3. Dias, L.C.; Pimenta, F.M.; Santos, A.B.; Costa, M.H.; Ladle, R.J. Patterns of land use, extensifification, and intensifification of Brazilian agriculture. Glob. Chang. Biol. 2016, 22, 2887-2903. [CrossRef]

4. Liu, J.; Zhang, Z.; Xu, X.; Kuang, W.; Zhou, W.; Zhang, S.; Jiang, N. Spatial patterns and driving forces of land use change in China during the early 21st century. J. Geogr. Sci. 2010, 20, 483-494. [CrossRef]

5. Temme, A.J.A.M.; Verburg, P.H. Mapping and modelling of changes in agricultural intensity in Europe. Agric. Ecosyst. Environ. 2011, 140, 46-56. [CrossRef]

6. Hyandye, C.; Mandara, C.G.; Safari, J. GIS and logit regression model applications in land use/land cover change and distribution in Usangu catchment. Int. J. Remote Sens. 2015, 3, 6-16. [CrossRef]

7. Ren, J.; Campbell, J.B.; Shao, Y. Spatial and temporal dimensions of agricultural land use changes, 2001-2012, East-Central Iowa. Agric. Syst. 2016, 148, 149-158. [CrossRef]

8. Shoyama, K.; Braimoh, A.K.; Avtar, R.; Saito, O. Land Transition and Intensity Analysis of Cropland Expansion in Northern Ghana. Environ. Manag. 2018, 62, 892-905. [CrossRef]

9. Najmuddin, O.; Deng, X.; Bhattacharya, R. The Dynamics of Land Use/Cover and the Statistical Assessment of Cropland Change Drivers in the Kabul River Basin, Afghanistan. Sustainability 2018, 10, 423. [CrossRef]

10. Arowolo, A.O.; Deng, X. Land use/land cover change and statistical modelling of cultivated land change drivers in Nigeria. Reg. Environ. Chang. 2018, 18, 247-259. [CrossRef]

11. Pérez-Hoyos, A.; García-Haro, F.J.; San-Miguel-Ayanz, J. Conventional and fuzzy comparisons of large-scale land cover products: Application to CORINE, GLC2000, MODIS and GlobCover in Europe. ISPRS J. Photogramm. Remote Sens. 2012, 74, 185-201. [CrossRef]

12. Briner, S.; Elkin, C.; Huber, R. Assessing the impacts of economic and climate changes on land-use in mountain regions: A spatial dynamic modeling approach. Agric. Ecosyst. Environ. 2012, 149, 50-63. [CrossRef]

13. Yao, Z.; Zhang, L.; Tang, S.; Li, X.; Hao, T. The basic characteristics and spatial patterns of global cultivated land change since the 1980s. J. Geogr. Sci. 2017, 27, 771-785. [CrossRef]

14. Alexander, P.; Rounsevell, M.D.; Dislich, C.; Dodson, J.R. Drivers for global agricultural land use change: The nexus of diet, population, yield and bioenergy. Glob. Environ. Chang. 2015, 35, 138-147. [CrossRef]

15. Meneses, B.M.; Reis, E.; Pereira, S.; Vale, M.J.; Reis, R. Understanding driving forces and implications associated with the land use and land cover changes in Portugal. Sustainability 2017, 9, 351. [CrossRef]

16. Bennetzen, E.H.; Smith, P.; Porter, J.R. Decoupling of greenhouse gas emissions from global agricultural production: 1970-2050. Glob. Chang. Biol. 2016, 22, 763-781. [CrossRef]

17. Li, W.W.; Chen, T.; Ma, X.L. Spatial hotspots' characteristics and mechanisms of the urban tourism and leisure industry in Xi'an City. Sci. Geogr. Sin. 2020, 40, 437-446. [CrossRef]

18. Wang, H.; Gao, J.; Hou, W. Quantitative attribution analysis of soil erosion in different morphological types of geomorphology in karst areas: Based on the geographical detector method. Acta Geogr. Sin. 2019, 29, 271-286. [CrossRef]

19. Liang, L.W.; Chen, M.X.; Luo, X.Y.; Xian, Y. Changes pattern in the population and economic gravity centers since the Reform and Opening up in China: The widening gaps between the South and North. J. Clean. Prod. 2021, 310, 127379. [CrossRef]

20. Yue, H.; Hu, T. Geographical Detector-Based Spatial Modeling of the COVID-19 Mortality Rate in the Continental United States. Int. J. Environ. Res. Public Health 2021, 18, 6832. [CrossRef]

21. Liu, C.L.; Li, W.L.; Zhu, G.F.; Zhou, H.K.; Yan, H.P.; Xue, P.F. Land Use/land cover changes and their driving factors in the Northeastern Tibetan Plateau based on geographical detectors and google earth engine: A case study in gannan prefecture. Remote Sens. 2020, 12, 3139. [CrossRef]

22. Han, J.J.; Wang, J.P.; Chen, L.; Xiang, J.Y.; Lin, Z.Y.; Li, Q.K.; Wang, E. Driving factors of desertification in Qaidam Basin, China: An 18-year analysis using the geographic detector model. Ecol. Indic. 2021, 124, 107404. [CrossRef]

23. Zhao, Y.; Ren, H.; Li, X. Forest Transition and Its Driving Forces in the Qian-Gui Karst Mountainous Areas. J. Resour. Ecol. 2020, 11, 59-68. [CrossRef]

24. Yu, H.; Yu, S.; He, D.; Lu, Y. Equity analysis of Chinese physician allocation based on Gini coefficient and Theil index. BMC Health Serv. Res. 2021, 21, 455. [CrossRef]

25. Guo, L.; Liu, R.; Men, C.; Wang, Q.R.; Miao, Y.X.; Shoaib, M.; Wang, Y.F.; Jiao, L.J.; Zhang, Y. Multiscale spatiotemporal characteristics of landscape patterns, hotspots, and influencing factors for soil erosion. Sci. Total Environ. 2021, 779, 146474. [CrossRef]

26. Song, Y.; Wang, J.; Ge, Y.; Xu, C.D. An optimal parameters-based geographical detector model enhances geographic characteristics of explanatory variables for spatial heterogeneity analysis: Cases with different types of spatial data. GIScience Remote Sens. 2020, 57, 593-610. [CrossRef]

27. Li, L.; Wang, H.H.; Wang, Y.G. Study on spatial distribution and change of County Cultivated Land in Sichuan Province. J. Leshan Norm. Univ. 2015, 30, 70-75. [CrossRef] 
28. Wang, X.; Yang, Q.; Zeng, Q.G.; Zhang, J.H.; Li, J.R.; Li, Y.R.; Zhu, Y.H. Evolution characteristics of temporal and spatial pattern of cultivated land in Sichuan Province from 1999 to 2018. Chin. Agron. Bull. 2021, 37, 110-116. [CrossRef]

29. Iqbal, M.A.; Penas, A.; Cano-Ortiz, A.; Kersebaum, K.C.; Herrero, L.; Del Rio, S. Analysis of recent changes in maximum and minimum temperatures in Pakistan. Atmos. Res. 2016, 168, 234-249. [CrossRef] 